\title{
Aspirin for the Primary Prevention of Myocardial Infarction: An Evidence- Based Clinical Inquiry
}

\author{
Brooklyn R. Nemetchek*
}

\begin{abstract}
Evidence is evaluated to determine whether low dose aspirin $(81 \mathrm{mg})$ for primary prevention in patients aged $50-65$ with no history of cardiovascular disease decreases the incidence of myocardial infarction. Ten studiesgiving relevant clinical evidence are identified and evaluated, with each gender looked at in isolation. The preliminary evidence of this paper suggests that aspirin for the primary prevention of myocardial infarction is not suitable for women aged 50-65, while it does hold benefits for males of the same age range (Howard, 2014). However, the evidence is not unanimous, and more research is needed before recommending aspirin for primary prevention in all low-risk individuals. In relation to aspirin for primary prevention of myocardial infarction, short- and long-term recommendations for nursing practice are developed and discussed, demonstrating the significant role the nurse plays in education, helping each patient to assess individual risks and benefits, and advising patients to consult their physician before self-medicating (Howard, 2014).
\end{abstract}

Keywords: aspirin, primary prevention, myocardial infarction, nursing

Cardiovascular disease is the number one cause of death globally, having claimed an estimated 17.5 million lives in 2012. Of those, coronary heart disease accounted for approximately 7.4 million deaths (World Health Organization [WHO], 2015). Cardiovascular disease describes disorders of the heart and blood vessels, including coronary heart disease, cerebrovascular diseases, peripheral arterial disease, rheumatic heart disease, congenital heart disease, and deep vein thrombosis (WHO, 2015). Myocardial infarction, a subgroup of coronary heart disease, occurs when a vessel supplying the heart is occluded, usually by a clot (WHO, 2015). A primary prevention strategy is long-term administration of aspirin for the purpose of preventing the first occurrence of cardiovascular disease, including, more particular to this paper, myocardial infarction (Kappagoda \& Amsterdam, 2011; American Society of Health-System Pharmacists [ASHP], 1997).

Aspirin (acetylsalicylic acid) is a potent and irreversible inhibitor of platelet aggregation because it reduces thrombosis (Gaziano \& Greenland, 2014). In platelets, the enzyme COX-1 produces thromboxane $\mathrm{A}_{2}$ which aids in platelet aggregation (Gaziano \& Greenland, 2014). COX-1 cannot be regenerated in platelets and is therefore permanently inhibited by aspirin, leading to a prolonged antithrombotic effect lasting several days after a single dose until enough new platelets have been produced to restore normal function (Gaziano \& Greenland, 2014). This unique property means aspirin is valuable in reducing the risk of thrombotic events such as myocardial infarction, but

*College of Nursing, University of Saskatchewan, Saskatoon, SK, Canada

Correspondence: brn139@mail.usask.ca

University of Saskatchewan Undergraduate Research Journal Volume 2, Issue 2, 2016 
also in increasing the possibility of bleeding, including gastrointestinal bleeding and hemorrhagic stroke (Gaziano \& Greenland, 2014). Aspirin has been shown to have benefits during acute events, after certain vascular procedures, and as secondary prevention of major vascular events for those with evidence of cardiovascular disease (Gaziano \& Greenland, 2014). The majority of the population taking aspirin for cardiovascular prevention use it for primary prevention (Howard, 2014). Approximately $20 \%$ of these individuals do so without medical recommendation (Howard, 2014), while the question remains whether aspirin is appropriate for everyone (Howard, 2014).

Health care practitioners, and nurses in particular, have a key role in ensuring aspirin is used safely. In order to evaluate aspirin and its potential benefits and harms for each patient, the nurse must be able to identify and solve problems related to body systems, interpret physical assessments and diagnostic data, be aware of the factors affecting safe nursing practice, and communicate interprofessionally in relation to the care of complex and high acuity patients. These nursing requirements are critical to the care of such a patient. Gaziano and Greenland (2014) note that "Given the beneficial effects of aspirin during acute events, following procedures, and in the secondary prevention of major vascular events among patients with cardiovascular disease, it was logical to ask whether this inexpensive drug could prevent the first myocardial infarction or stroke among persons who have yet to manifest vascular disease". Evidence will be evaluated to determine whether or not low dose aspirin $(81 \mathrm{mg})$ for primary prevention decreases the incidence of myocardial infarction in patients between the ages of 50 and 65 with no history of cardiovascular disease.

\section{Methodology}

Randomized control trials (RCTs) have been conducted on the issue with varying populations, dosages of aspirin, controls, and outcomes. Meta-analysis of RCTs themselves have resulted in differences in terms of recommendations for practice. Results are based on studies of primarily white males or health care providers, which limited the generalizability of the findings (Howard, 2014). Therefore, there is a need for further study regarding particular ages, populations, and subpopulations (for example, women age 65 and older as compared to women aged 50-65). A literature review was conducted using Medline and Cumulative Index to Nursing and Allied Health (CINAHL), using the key phrases of "myocardial infarction," "primary prevention," and "aspirin." Studies looking at aspirin's effect on primary occurrence of myocardial infarction were included. Studies looking only at other potential outcomes of aspirin use, such as incidence of stroke and bleeding, were not included.

\section{Results}

Eleven studies giving relevant clinical evidence were identified and are presented in Table 3, evaluated alphabetically by author. The level of evidence for each study was recognized with the use of Table 2 . To examine the evidence, it is helpful to look at each gender in isolation, as significant differences have been observed.

Table 1: PICO Question Format for Aspirin as a Prevention of Myocardial Infarction

\begin{tabular}{|l|l|}
\hline Patient or problem & Individuals (both men and women) between the ages of 50and 65 with no history of cardiovascular disease. \\
\hline Intervention & $\begin{array}{l}\text { Low-dose aspirin (81mg) for primary prevention. 81mg is the lowest readily available dose in chewable } \\
\text { tablets and enteric-coated tablet forms (Lippincott Williams \& Wilkins, 2005, p. 355). 75-10omg has been } \\
\text { shown to be the optimum dosage range due to its maximal inhibition of platelet aggregation while giving } \\
\text { minimal side effects (Hennekens, Manson \& Reilly, 2002). }\end{array}$ \\
\hline Comparison & $\begin{array}{l}\text { No aspirin treatment or placebo. Comparisons made to other antiplatelet therapies, although they may be } \\
\text { present in the research articles examined, are not included in this analysis. }\end{array}$ \\
\hline Outcome & $\begin{array}{l}\text { Decreased incidence of myocardial infarction. Although other outcomes such as bleeding are possible, the } \\
\text { paper looks solely at the incidence of myocardial infarction for an indication of an outcome. }\end{array}$ \\
\hline
\end{tabular}


Table 2: Levels of Evidence for Prevention Medicine

\begin{tabular}{|c|l|}
\hline Level & Type of Evidence \\
\hline $1 a$ & Systematic review of Randomized Control Trials (RCTs) \\
\hline $1 b$ & Individual RCT (with narrow confidence intervals) \\
\hline $1 c$ & All or none study \\
\hline $2 a$ & Systematic review (with homogeneity) of cohort studies \\
\hline $2 b$ & Individual cohort study (including low quality RCT, e.g., <80\% follow-up) \\
\hline $2 c$ & "Outcomes" research; Ecological studies \\
\hline $3 a$ & Systematic review (with homogeneity) of case-control studies \\
\hline $3 b$ & Individual case-control study \\
\hline 4 & Case series (and poor quality cohort and case-control study) \\
\hline 5 & Expert opinion without explicit critical appraisal, or based on physiology bench research or "first principles" \\
\hline
\end{tabular}

(Howick, 2009)

Table 3a: Evaluation of Source and Level of Evidence

\begin{tabular}{|c|c|}
\hline & Article 1 \\
\hline Reference & $\begin{array}{l}\text { Antithrombotic Trialists' Collaboration. (2002). Collaborative meta-analysis of randomized trials of } \\
\text { antiplatelet therapy for prevention of death, myocardial infarction, and stroke in high-risk patients. } \\
\text { British Medical Journal, 324(7329), 71-86. doi: } 10.1136 / \mathrm{bmj} .324 .7329 .71\end{array}$ \\
\hline Research Design & $\begin{array}{l}\text { Collaborative meta-analyses of } 287 \text { studies (197 comparing anti-platelet verses control; } 90 \\
\text { comparing different antiplatelet regimens). }\end{array}$ \\
\hline Setting & Varied. \\
\hline Sample/Population & $\begin{array}{l}(\mathrm{N}=135000) \text { patients in comparisons of antiplatelet therapy versus control. } \\
(\mathrm{N}=77000) \text { patients in comparisons of different antiplatelet regimens. }\end{array}$ \\
\hline Aspirin & Varied dosages. \\
\hline Comparison & Placebo, no aspirin, or other antiplatelet therapy. \\
\hline $\begin{array}{l}\text { Recommendations } \\
\text { and/or Limitations }\end{array}$ & $\begin{array}{l}\text { An unanswered question is whether it is possible to identify particular groups of apparently healthy } \\
\text { people who may be at increased risk of myocardial infarction or stroke and for whom the benefits of } \\
\text { daily aspirin outweigh the risks. } \\
\text { Adding a second antiplatelet drug to aspirin may produce additional benefits in some clinical } \\
\text { circumstances, but more research into this strategy is needed. } \\
\text { Aspirin dose, duration of treatment, and lengths of follow-up were not uniform. } \\
\text { Meta-analysis remains a retrospective research subject to the methodological deficiencies of the } \\
\text { included studies. }\end{array}$ \\
\hline
\end{tabular}


Table 3b: Evaluation of Source and Level of Evidence

\begin{tabular}{|c|c|}
\hline & Article 2 \\
\hline Reference & $\begin{array}{l}\text { Bartolucci, A., Tendera, M., \& Howard, G. (2011). Meta-analysis of multiple primary prevention trials } \\
\text { of cardiovascular events using aspirin. The American Journal of Cardiology,107(12), 1796-1801. } \\
\text { doi:10.1016/j.amjcard.2011.02.325 }\end{array}$ \\
\hline Level of Evidence & $1 a$ \\
\hline Research Design & $\begin{array}{l}\text { Analysis of nine randomized trials evaluating the benefits of aspirin for primary prevention of } \\
\text { cardiovascular events: } \\
\begin{array}{c}\text { - } \\
\text { - }\end{array} \text { The British Doctor's Trial (BMD) } \\
\text { - } \quad \text { The Thrombosis Prevention Trial (TPT) } \\
\text { - } \quad \text { The Hypertension Optimal Treatment (HOT) study } \\
\text { - } \quad \text { The Primary Prevention Project (PPP) } \\
\text { - } \quad \text { The Women's Health Study (WHS) } \\
\text { - } \quad \text { The Aspirin for Asymptomatic Atherosclerosis Trial (AAAT) } \\
\text { - } \quad \text { The Prevention of Progression of Arterial Disease and Diabetes (POPADAD) trial } \\
\text { - } \quad \text { The Japanese Primary Prevention of Atherosclerosis with Aspirin for Diabetes (JPAD) trial }\end{array}$ \\
\hline Setting & Varied. \\
\hline Sample/Population & Both genders, varying age and medical history. \\
\hline Aspirin & $(\mathrm{N}=50$ 868). Varying dosage: $75-325 \mathrm{mg}$ \\
\hline Comparison & $(\mathrm{N}=49$ 170). Placebo or no aspirin. \\
\hline Findings & $\begin{array}{l}\text { Primary prevention with aspirin decreased the risk for total cardiovascular events and nonfatal MI, } \\
\text { but there were no significant differences in the incidences of stroke, cardiovascular mortality, all- } \\
\text { cause mortality, and total coronary heart disease. }\end{array}$ \\
\hline $\begin{array}{l}\text { Recommendations } \\
\text { and/or Limitations }\end{array}$ & $\begin{array}{l}\text { Aspirin dose, duration of treatment, and lengths of follow-up were not uniform. } \\
\text { Meta-analysis remains a retrospective research subject to the methodological deficiencies of the } \\
\text { included studies. }\end{array}$ \\
\hline
\end{tabular}


Table 3c: Evaluation of Source and Level of Evidence

\begin{tabular}{|c|c|}
\hline & Article 3 \\
\hline Reference & $\begin{array}{l}\text { Berger, J., Roncaglioni, M., Avanzini, F., Pangrazzi, I., Tognoni, G. \& Brown, D. (2006). Aspirin for the } \\
\text { primary prevention of cardiovascular events in women and men: A sex-specific meta-analysis of } \\
\text { randomized controlled trials. The Journal of the American Medical Association, 295(3), 306-13. } \\
\text { doi:10.1001/jama.295.3.306 }\end{array}$ \\
\hline Level of Evidence & $1 a$ \\
\hline Research Design & $\begin{array}{l}\text { Meta-analysis of six randomized controlled trials of aspirin therapy in participants without } \\
\text { cardiovascular disease that reported data on myocardial infarction (MI), stroke, and cardiovascular } \\
\text { mortality. } \\
\text { - } \quad \text { Physician's Health Study (1989) } \\
\text { - } \quad \text { British Doctor's Trial (1988) } \\
\text { - } \quad \text { Thrombosis Prevention Trial (1998) } \\
\text { - } \quad \text { Hypertension Optimal Treatment Trial (1998) } \\
\text { - } \quad \text { Primary Prevention Project (2001) } \\
\text { - } \quad \text { Women's Health Study (2005) }\end{array}$ \\
\hline Setting & Varied. \\
\hline Sample/Population & $\begin{array}{l}(\mathrm{N}=95456 \text { total): } 3 \text { trials included only men, } 1 \text { included only women, and } 2 \text { included both sexes. } 51 \\
342 \text { were women. }\end{array}$ \\
\hline Aspirin & $\begin{array}{l}75 \mathrm{mg} / \text { day ( } 2 \text { trials) } \\
\text { 10omg every other day ( } 1 \text { trial) } \\
\text { 10omg/day ( } 1 \text { trial) } \\
325 \mathrm{mg} \text { every other day ( } 1 \text { trial) } \\
500 \mathrm{mg} / \text { day ( } 1 \text { trial) }\end{array}$ \\
\hline Comparison & Varied. Placebo or no aspirin. \\
\hline Findings & $\begin{array}{l}\text { For women and men, aspirin therapy reduced the risk of a composite of cardiovascular events due to } \\
\text { its effect on reducing the risk of ischaemic stroke in women and } \mathrm{Ml} \text { in men. Aspirin significantly } \\
\text { increased the risk of bleeding to a similar degree among women and men. }\end{array}$ \\
\hline
\end{tabular}


Table 3d: Evaluation of Source and Level of Evidence

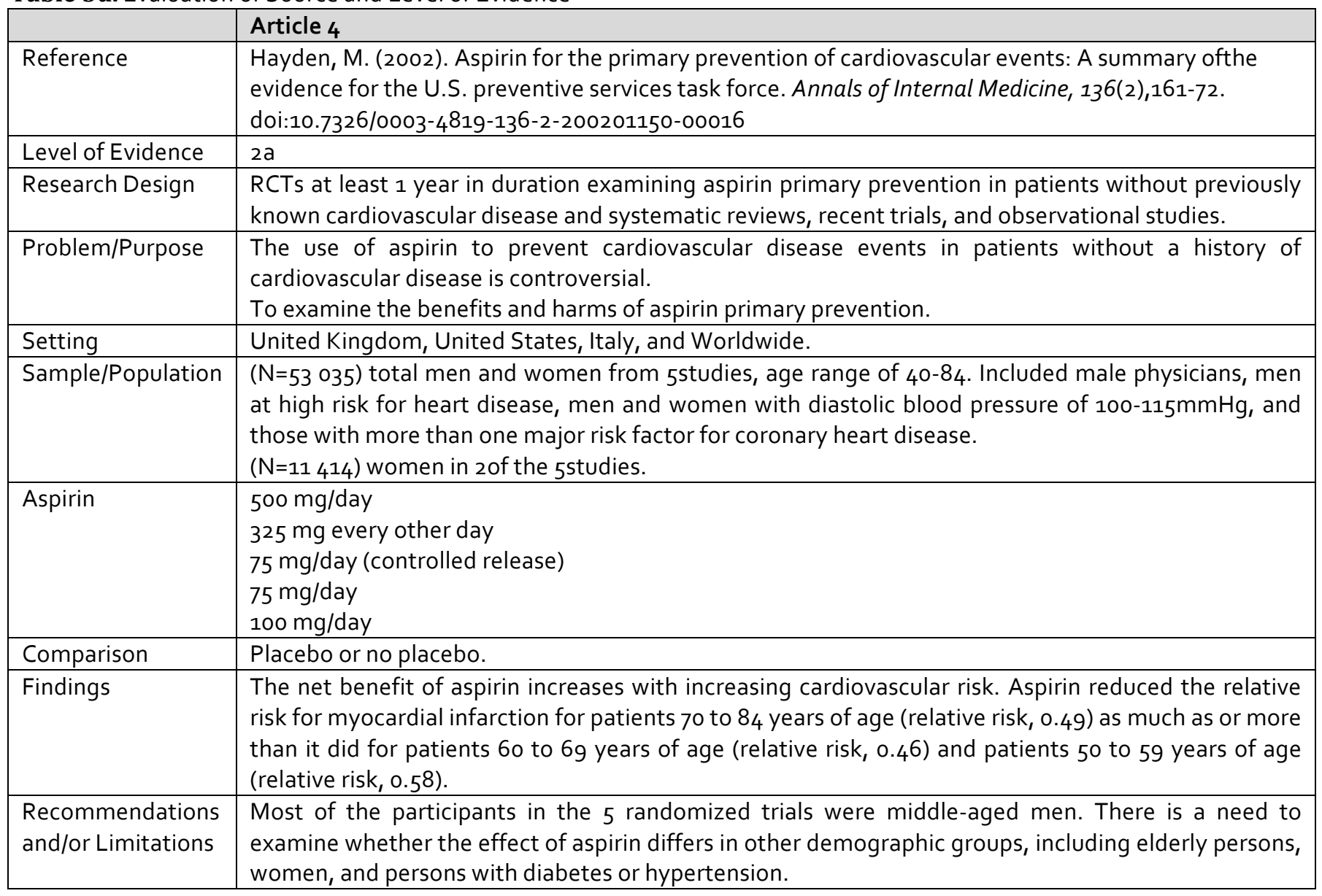

Table 3e: Evaluation of Source and Level of Evidence

\begin{tabular}{|c|c|}
\hline & Article 5 \\
\hline Reference & $\begin{array}{l}\text { Howard, P. A. (2014). Aspirin for primary cardiovascular prevention: When is it worth the risks? } \\
\text { Hospital Pharmacy, 49(6), 502-507. doi:10.1310/hpj4906-502 }\end{array}$ \\
\hline Level of Evidence & 5 \\
\hline Research Design & $\begin{array}{l}\text { Review of evidence, including trials and meta-analysis, recommendations, issues to be resolved, and } \\
\text { pathophysiology. }\end{array}$ \\
\hline Problem/Purpose & $\begin{array}{l}\text { It has become increasingly clear that aspirin may not be appropriate for everyone. This article reviews } \\
\text { current evidence, recommendations, and issues that have yet to be resolved. }\end{array}$ \\
\hline Setting & Varied. \\
\hline Sample/Population & Varied. \\
\hline Aspirin & Varied dosage. \\
\hline Comparison & Varied, including placebo. \\
\hline Findings & $\begin{array}{l}\text { Current evidence has not provided definitive proof of aspirin's effectiveness for primary prevention } \\
\text { among those with low baseline risk. }\end{array}$ \\
\hline
\end{tabular}


Table 3f: Evaluation of Source and Level of Evidence

\begin{tabular}{|c|c|}
\hline & Article 6 \\
\hline Reference & $\begin{array}{l}\text { Ikeda, Y., Shimada, K., Teramoto, T., Uchiyama, S., Yamazaki, T., Oikawa, S., \& ... Ishizuka, N. } \\
\text { (2014). Low-dose aspirin for primary prevention of cardiovascular events in Japanese patients } 60 \\
\text { years or older with atherosclerotic risk factors: A randomized clinical trial. JAMA: Journal of the } \\
\text { American Medical Association, 312(23), 2510-2520. doi:10.1001/jama.2014.15690. }\end{array}$ \\
\hline Level of Evidence & $2 b$ \\
\hline Research Design & Open-label, randomized (1:1), parallel-group trial over 5 years. \\
\hline Setting & 1007 clinics in Japan. \\
\hline Sample/Population & $\begin{array}{l}\text { Japanese patients ( } \mathrm{N}=14464) \text { aged } 60 \text { to } 85 \text { years, presenting with hypertension, dyslipidemia, or } \\
\text { diabetes mellitus. }\end{array}$ \\
\hline Aspirin & Enteric-coated aspirin, 100mg/day. \\
\hline $\begin{array}{l}\text { Recommendations } \\
\text { and/or Limitations }\end{array}$ & $\begin{array}{l}\text { Study terminated early based on a futility assessment; however, an exploratory analysis suggested a } \\
28 \% \text { probability of finding a significant difference in favour of aspirin had the study been continued } \\
\text { through the planned number of events. } \\
\text { There was a decreasing level of adherence with daily low-dose aspirin in the aspirin group (dropping } \\
\text { to } 76 \% \text { in year 5) and increasing uptake of daily aspirin in the no aspirin group (10\% by year } 5 \text { ). } \\
\text { The study was not blinded and did not have a placebo control due to Japanese ethical standards, and } \\
\text { the drop-in rate and rate of patients lost to follow-up were about } 10 \% \text {. The role that enteric coating } \\
\text { might have on the efficacy of low-dose aspirin is not clear. }\end{array}$ \\
\hline
\end{tabular}

Table 3g: Evaluation of Source and Level of Evidence

\begin{tabular}{|c|c|}
\hline & Article 7 \\
\hline Reference & $\begin{array}{l}\text { Juul-Möller, S., Edvardsson, N., Jahnmatz, B., Rosén, A., Sørensen, S., \& Omblus, R. (1992). Double- } \\
\text { blind trial of aspirin in primary prevention of myocardial infarction in patients with stable chronic } \\
\text { angina pectoris. The Swedish Angina Pectoris Aspirin Trial (SAPAT) Group. Lancet, 340(8833), 1421- } \\
\text { 1425. doi:10.1016/0140-6736(92)92619-Q }\end{array}$ \\
\hline Level of Evidence & $1 b$ \\
\hline Research Design & Randomized, double blind. \\
\hline Setting & Sweden. \\
\hline Sample/Population & Patients $(\mathrm{N}=2035)$ aged $30-80$ who demonstrated chest pain on exertion for at least 1 month. \\
\hline Aspirin & $75 \mathrm{mg} /$ day and sotalol for angina symptoms. \\
\hline Comparison & Placebo and sotalol for angina symptoms. \\
\hline $\begin{array}{l}\text { Recommendations } \\
\text { and/or Limitations }\end{array}$ & $\begin{array}{l}\text { Further study is needed to determine the effects of aspirin by itself with the same population, } \\
\text { without the use of sotalol or other medications of its kind. }\end{array}$ \\
\hline
\end{tabular}


Table 3h: Evaluation of Source and Level of Evidence

\begin{tabular}{|c|c|}
\hline & Article 8 \\
\hline Reference & $\begin{array}{l}\text { Manson, J., Stampfer, M., Colditz, G., Willett, W., Rosner, B., Speizer, F., \& Hennekens, C. (1991). A } \\
\text { prospective study of aspirin use and primary prevention of cardiovascular disease in women. The } \\
\text { Journal of the American Medical Association, 266(4), 521-527. } \\
\text { doi:10.1001/jama.1991.03470040085027. }\end{array}$ \\
\hline Level of Evidence & $2 b$ \\
\hline Research Design & $\begin{array}{l}\text { Prospective cohort study including } 6 \text { years of follow-up, from } 1980 \text { to } 1986 \text {. Participants responded } \\
\text { to questionnaires regarding medical history and lifestyle. }\end{array}$ \\
\hline Setting & Eleven U.S. states. \\
\hline $\begin{array}{l}\text { Sample/Populatio } \\
\mathrm{n}\end{array}$ & $\begin{array}{l}(\mathrm{N}=87678) \text { United States registered nurses aged } 34 \text { to } 65 \text { years free of diagnosed coronary heart } \\
\text { disease, stroke, and cancer at baseline. }\end{array}$ \\
\hline $\begin{array}{l}\text { Recommendations } \\
\text { and/or Limitations }\end{array}$ & $\begin{array}{l}\text { Approximately } 98 \% \text { of the cohort was white. The self-reporting nature of the study may have } \\
\text { provided untrue data (over-stating or under-stating how much aspirin is taken each week). The } \\
\text { dosage of 1pill of aspirin ( } 325 \mathrm{mg} \text { ) was not provided to the participants, they were simply asked how } \\
\text { many aspirin they take per week and responded accordingly. }\end{array}$ \\
\hline
\end{tabular}

Table 3i: Evaluation of Source and Level of Evidence

\begin{tabular}{|l|l|}
\hline & Article 9 \\
\hline Reference & $\begin{array}{l}\text { Raju, N., Sobieraj-Teague, M., Hirsh, J., O'Donnell M., Eikelboom, J. (2011). Effect of aspirin on } \\
\text { mortality in the primary prevention of cardiovascular disease. The American Journal of Medicine, } \\
124(7), 621-629 .\end{array}$ \\
\hline Level of Evidence & 12 \\
\hline Research Design & Meta-analysis of nine randomized controlled trials. \\
\hline Problem/Purpose & To obtain best estimates of the effect of aspirin on mortality in primary prevention. \\
\hline Setting & Varied. \\
\hline Sample/Population & (N=10o o76 total). Patients without a history of symptomatic cardiovascular disease. \\
\hline Aspirin & Varied dosages (75-50omg/day or alternate days). \\
\hline Comparison & Placebo or no aspirin treatment. \\
\hline Findings & $\begin{array}{l}\text { Aspirin prevents deaths, myocardial infarction, and ischaemic stroke, and increases hemorrhagic } \\
\text { stroke and major bleeding when used in the primary prevention of cardiovascular disease. }\end{array}$ \\
\hline $\begin{array}{l}\text { Recommendations } \\
\text { and/or Limitations }\end{array}$ & $\begin{array}{l}\text { Included studies were conducted over a 30-year period. } \\
\text { Aspirin dose, duration of treatment, and lengths of follow-up were not uniform. } \\
\text { Meta-analysis remains a retrospective research subject to the methodological deficiencies of the } \\
\text { included studies. }\end{array}$ \\
\hline
\end{tabular}


Table 3j: Evaluation of Source and Level of Evidence

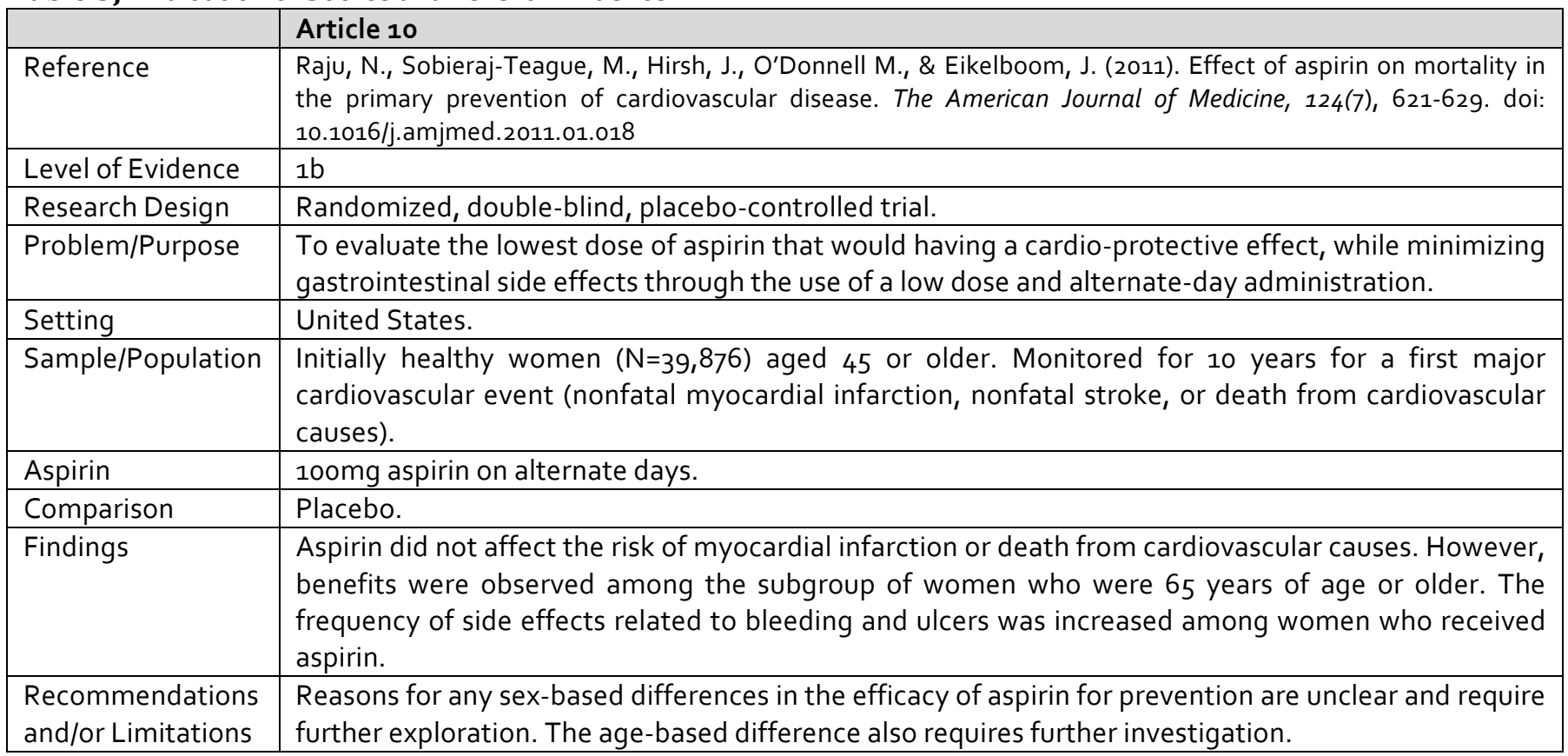

Table 3k: Evaluation of Source and Level of Evidence

\begin{tabular}{|c|c|}
\hline & Article 11 \\
\hline Reference & $\begin{array}{l}\text { Wolff, T., Miller, T., \&Ko, S. (2009). Aspirin for the primary prevention of cardiovascular events: An } \\
\text { update of the evidence for the U.S. preventive services task force.Annals of Internal Medicine, 150(6), } \\
\text { 405-410. doi:10.7326/0003-4819-150-6-200903170-00009 }\end{array}$ \\
\hline Level of Evidence & $2 a$ \\
\hline Research Design & $\begin{array}{l}\text { Randomized controlled trials (RCTs), case-control, meta-analysis, and systematic reviews of aspirin } \\
\text { versus control for the primary prevention of cardiovascular disease. }\end{array}$ \\
\hline Setting & Varied (including the United States, United Kingdom, and Italy). \\
\hline Sample/Population & Individuals without history of cardiovascular disease. \\
\hline Aspirin & Varying dosage from $75 \mathrm{mg} / \mathrm{d}$ to $500 \mathrm{mg} / \mathrm{d}$. The Women's Health Study used $100 \mathrm{mg}$ every other day. \\
\hline Comparison & Placebo or no aspirin. \\
\hline $\begin{array}{l}\text { Recommendations } \\
\text { and/or Limitations }\end{array}$ & $\begin{array}{l}\text { The dose of aspirin used in the RCTs varied, preventing the estimation of the best dose for primary } \\
\text { prevention. Several of the RCTs were performed in health professionals, potentially limiting } \\
\text { generalizability. } \\
\text { Aspirin dose, duration of treatment, and lengths of follow-up were not uniform. }\end{array}$ \\
\hline
\end{tabular}




\section{Discussion of Results}

More research needs to be conducted, but preliminary evidence suggests aspirin has no benefit for primary prevention of myocardial infarction in women between the ages of 50 and 65 (Ridker, 2005). The study consisted of 39 876 initially healthy women age 45 or older who were monitored for 10 years and given 10omg of aspirin on alternate days or a placebo. The low dose used in the study by Ridker (2005) could be suggested as a potential reason why no effect was seen in regards to the reduction of $\mathrm{Ml}$. However, the meta-analysis conducted by Berger et al. (2006) found similarly that although aspirin reduced $\mathrm{Ml}$ in men, it did not have a significant effect for women in reducing the incidence of $\mathrm{Ml}$. The same study by Ridker (2005) found that, in the subpopulation of healthy females over the age of 65 , aspirin did reduce the incidence of MI. Although more research is needed, the preliminary evidence suggests that aspirin as primary prevention for $\mathrm{MI}$ is not recommended for those healthy women with no precipitating factors (Ridker, 2005).

There have been many studies done primarily on men in regards to aspirin and its usefulness for the primary prevention of MI. The Antithrombotic Trialists' Collaboration (2002), Bartolucci et al. (2011), Berger et al. (2006), Hayden (2002), Raju et al. (2011), and Wolff, Miller, and Ko (2009) concluded that low-dose aspirin does, in fact, decrease incidence of myocardial infarction when used as primary prevention for men. The trial done by Juul-Moller et al. (1992) concluded that low-dose aspirin in 2035 patients aged 30 to 80 with chronic stable angina significantly reduced myocardial infarction and has been examined in some of the meta-analysis. Other trials included in the many analyses were conducted from 1988-2014; the broad range of dates makes it difficult to perform a homogenous analysis of the evidence due to the various research techniques, populations, dosages of aspirin, and other circumstances of life such as control of adjuvant medications and lifestyle factors.

Although the studies discussed above determine that aspirin does have a benefit, Ikeda et al. (2014) and Howard (2014) conclude that the current evidence is not definitive proof of aspirin's efficacy in prevention for those at low risk. In fact, the study conducted by lkeda et al. (2014) found that low dose aspirin did not have any significant impact on reducing the risk of myocardial infarction. It should be noted, however, that this study was done on a Japanese population; this population has been shown to have a lower overall incidence of myocardial infarction risk factors such as smoking and increased body mass index (BMI), leading to a lower incidence of myocardial infarction than in white males of the Western population (Ikeda et al., 2014). The study also terminated early, was not blinded, and did not have a placebo control due to Japanese ethical standards (Ikeda et al., 2014). These factors may have contributed to the fact that the no-aspirin group experienced a $10 \%$ increase in the uptake of aspirin by the $5^{\text {th }}$ year (lkeda et al., 2014). It is important to note that this does not mean aspirin is not effective for primary prevention, but rather more information is needed to establish substantial evidence specifically for those at low risk (Howard, 2014).

An important factor when looking at any benefit of aspirin in the primary prevention of myocardial infarction for both males and females between the ages of 50 and 65 is to examine any adverse effects of the therapy in question. In every trial and meta-analysis evaluated, the incidence of bleeding, specifically gastrointestinal bleeds and hemorrhagic stroke, increased with the use of aspirin in comparison to the control group. Although the outcome examined for this paper was solely the incidence of myocardial infarction, it is important to note that all risks and benefits must be weighed in collaboration with a health professional when deciding whether or not to take aspirin (Gaziano \& Greenland, 2014).

\section{Summary and Recommendations for Practice}

Although current evidence has not provided definitive proof of the effectiveness of aspirin for the primary prevention of myocardial infarction for every individual with no previous cardiovascular disease, the preliminary evidence of this paper suggests aspirin for the primary prevention of myocardial infarction is not suitable for women aged 50 to 65 , while it does hold benefits for males of the same age range (Howard, 2014). However, the evidence is not unanimous, and more research is needed before the decision can be made to recommend aspirin for primary prevention in all low-risk individuals. The U.S. Preventive Services Task Force (2009) recommendations regarding aspirin for primary prevention based on 10-year cardiovascular risk exemplifies how prescription by a physician needs to be done with each patient in conjunction with the best evidence and with consideration of the individual overall risk assessment (Gaziano \& Greenland, 2014).

Nurses in acute care settings need to be educated on aspirin and the current evidence on its use for primary prevention, and made aware of the prevalence of selfmedication in patient populations. The nurse has a significant role to play in education, helping each patient to assess individual risks and benefits, and in advising patients to consult their physician before self-medicating (Howard, 2014). Nurses must do a thorough medication screen with every patient, as aspirin can have many implications for the acute care setting regardless of dosage (Howard, 2014). The 
increased risk of bleeding caused by aspirin can be detrimental if not taken into account before surgery and other procedures (Gaziano \& Greenland, 2014; Lippincott Williams \& Wilkins, 2005). For short- and long-term recommendations for nursing practice as well as their supports and barriers, refer to Table 4. Although the current evidence is not clear enough to determine definitively who should or should not be on aspirin, the nurse is a trusted professional who does have the vital role of educating each patient about not only aspirin and its risks and benefits, but also every medication, procedure, and diagnosis.

1. During the acute phase (short-term): Identification of aspirin use upon the preliminary assessment. This may be supported by the utilization of a question specifically for aspirin use on the initial assessment form along with the other current medications.

\begin{tabular}{l|l} 
Supports & Barriers \\
\hline
\end{tabular}

- $\quad$ Aspirin affects bleeding, which has a significant impact on

- The time constraints of the acute period of care can many procedures in the acute period (Gaziano \& Greenland, 2014).

- Aspirin has the potential to interact with other drugs, specifically with other anticoagulants. Identification upon first assessment helps ensure safety with medication prescription and administration.

- Prompt identification can ensure that screening is not forgotten in the later period of care.

- Chronic, low-dose aspirin administration can be a cause of gastrointestinal bleeds or hemorrhagic stroke (Gaziano \& Greenland, 2014). Early identification of the cause of bleeding leads to better patient outcomes.

2. After the acute phase or when an opportunity presents itself (long-term): Provide education on aspirin's risks and benefits, including an individual cardiovascular risk assessment for both those individuals on aspirin for primary prevention as well as those who may benefit from aspirin for primary prevention of myocardial infarction according to current evidence (Howard, 2014). Education may be facilitated through the use of a pamphlet or brochure about aspirin. Referral to the primary physician is warranted for all individuals who are taking aspirin or who are considering taking aspirin (Howard, 2014).

\begin{tabular}{l|l} 
Supports & Barriers
\end{tabular}

- $\quad$ Education enables patients to make informed health care decisions (Howard, 2014).

- $\quad$ Those individuals on aspirin for primary prevention may not have received the proper education about the medication and its risks and benefits, and their own risks for myocardial infarction (Howard, 2014).

- Those individuals who are not taking aspirin prophylactically may already be considering taking it. Proper education can lead those individuals to seeking their physician's counsel.

- Those individuals who are not taking aspirin for primary prevention may be at such a risk for myocardial infarction that aspirin is warranted. Proper education and screening can lead these individuals to consult their physician on the matter.

- Consulting with a physician leads to more informed and safe health care decisions (Howard, 2014). It also ensures that the physician is aware of any aspirin being taken by the individual and can use that information when prescribing other medications, or procedures.

- A pamphlet or brochure enables a person to take the information home and review it, rather than depending solely on memory of the teaching conversation with a nurse.

- The time constraints of the acute period of care can make patient education less of a priority.

- Lack of nurse education around current evidence surrounding aspirin for primary prophylaxis of myocardial infarction could lead nurses to not teaching their patients, or providing them with outdated information.

- Not all individuals a nurse sees have ready access to a physician.

- Not all individuals can read a pamphlet or brochure.

- $\quad$ The healthcare practitioner who takes the medication history must ask not only about prescription medications, but also over-the-counter (OTC) drugs, vitamins, supplements, traditional medicines, and herbal preparations. 


\section{References}

Antithrombotic Trialists' Collaboration. (2002).

Collaborative meta-analysis of randomized trials of antiplatelet therapy for prevention of death, myocardial infarction, and stroke in high-risk patients. British Medical Journal, 324(7329), 71-86. doi: $10.1136 / \mathrm{bmj} \cdot 324.7329 \cdot 71$

American Society of Health-System Pharmacists (1997). ASHP therapeutic position statement on the use of aspirin for prophylaxis of myocardial infarction. American Journal of Health-System Pharmacy, 54(17), 1984-1987.

Bartolucci, A., Tendera, M., \& Howard, G. (2011). Metaanalysis of multiple primary prevention trials of cardiovascular events using aspirin. The American Journal of Cardiology, 107(12), 1796-1801. doi:10.1016/j.amjcard.2011.02.325

Berger, J., Roncaglioni, M., Avanzini, F., Pangrazzi, I., Tognoni, G. \& Brown, D. (2006). Aspirin for the primary prevention of cardiovascular events in women and men: A sex-specific meta-analysis of randomized controlled trials. The Journal of the American Medical Association, 295(3), 306-13. doi:10.1001/jama.295.3.306

Gaziano, J. M., \& Greenland, P. (2014). When should aspirin be used for prevention of cardiovascular events? Journal of the American Medical Association, 312(23), 2503-2504. doi:10.1001/jama.2014.16047

Hayden, M. (2002). Aspirin for the primary prevention of cardiovascular events: A summary of the evidence for the U.S. preventive services task force. Annals of Internal Medicine, 136(2), 161-72. doi:10.7326/0003-4819-136-2-200201150-00016

Hennekens, C., Manson, J., \& Reilly, M. (2002). Who should be taking aspirin? Patient Care, 36(13), 58.

Howard, P. A. (2014). Aspirin for primary cardiovascular prevention: When is it worth the risks? Hospital Pharmacy, 49(6), 502-507. doi:10.1310/hpj4906-502

Howick, J. (2009). Oxford Centre for Evidence-based Medicine - Levels of Evidence. Accessed from http://www.cebm.net/oxford-centre-evidencebased-medicine-levels-evidence-march-2009/
Ikeda, Y., Shimada, K., Teramoto, T., Uchiyama, S., Yamazaki, T., Oikawa, S., \& ... Ishizuka, N. (2014). Low-dose aspirin for primary prevention of cardiovascular events in Japanese patients 60 years or older with atherosclerotic risk factors: $A$ randomized clinical trial. JAMA: Journal of the American Medical Association, 312(23), 2510-2520. doi:10.1001/jama.2014.1569o.

Juul-Möller, S., Edvardsson, N., Jahnmatz, B., Rosén, A., Sørensen, S., \& Omblus, R. (1992). Double-blind trial of aspirin in primary prevention of myocardial infarction in patients with stable chronic angina pectoris. The Swedish Angina Pectoris Aspirin Trial (SAPAT) Group. Lancet, 340(8833), 1421-1425. doi:10.1016/0140-6736(92)92619-Q

Kappagoda, C.T., \& Amsterdam, E.A. (2011). Trials of primary prevention of cardiovascular events using aspirin. The American Journal of Cardiology, 108(8), 1198-1200. doi: 10.1016/j.amjcard.2011.07.035

Lippincott Williams \& Wilkins. (2005). Nursing 2005 Drug Handbook. Ambler, PA: Author. Ed. 25, p. 355-358.

Manson, J., Stampfer, M., Colditz, G., Willett, W., Rosner, B., Speizer, F., \& Hennekens, C. (1991). A prospective study of aspirin use and primary prevention of cardiovascular disease in women. The Journal of the American Medical Association, 266(4), 521-527. doi:10.1001/jama.1991.03470040085027.

Raju, N., Sobieraj-Teague, M., Hirsh, J., O’Donnell M., \& Eikelboom, J. (2011). Effect of aspirin on mortality in the primary prevention of cardiovascular disease. The American Journal of Medicine, 124(7), 621-629. doi: 10.1016/j.amjmed.2011.01.018

Ridker, P. M. (2005). A randomized trial of low-dose aspirin in the primary prevention of cardiovascular disease in women. The New England journal of medicine 352(13), 1293-1304. doi: 10.1056/NEJMoa050613

U.S. Preventive Services Task Force. (2009). Aspirin for the prevention of cardiovascular disease: U.S. preventive services task force recommendation statement. Annals of Internal Medicine, 150(6), 396404. doi:10.7326/0003-4819-150-6-20090317000008 . 
Wolff, T., Miller, T., \& Ko, S. (2009). Aspirin for the primary prevention of cardiovascular events: An update of the evidence for the U.S. preventive services task force. Annals of Internal Medicine, 150(6), 405-410. doi:10.7326/0003-4819-150-6-200903170-00009

World Health Organization (2015). Cardiovascular diseases (CVDs). Retrieved from http://www.who.int/mediacentre/factsheets/fs317/ en/ 
